\title{
Ceramide channel: structural basis for selective membrane targeting
}

\author{
Meenu N. Perera $^{a \ddagger}$, Vidyaramanan Ganesan $^{\text {a }}$, Leah J. Siskind ${ }^{b}$, \\ Zdzislaw M. Szulc ${ }^{c}$, Alicja Bielawska ${ }^{c}$, Robert Bittman ${ }^{d}$, and Marco \\ Colombini $^{\mathrm{a}^{*}}$
}
a. Department of Biology, University of Maryland
b. Department of Pharmacology and Toxicology, University of Louisville
c. Department of Biochemistry \& Molecular Biology, Medical University of South
Carolina
d. Department of Chemistry and Biochemistry, City University of New York, Queens College

‡. These authors contributed equally to this work.

* to whom correspondence should be addressed

Corresponding author: Marco Colombini

Address: Department of Biology, University of Maryland, College Park, Maryland, 20742

Telephone: 301-405-6925

Fax: 301-314-9358

E-mail: colombini@umd.edu 


\begin{abstract}
:
A ceramide commonly found in mammalian cells, $\mathrm{C}_{16}$-ceramide ( $N$-palmitoyl-D-erythrosphingosine), is capable of forming large, protein-permeable channels in the mitochondrial outer membrane (MOM). However, $\mathrm{C}_{16}$-ceramide is unable to permeabilize the plasma membrane of erythrocytes. This specificity is unexpected considering that ceramide forms channels in simple phosphoglycerolipid membranes. Synthetic analogs of $\mathrm{C}_{16}$-ceramide with targeted changes at each of the functional regions of the molecule including methylation, altered hydrocarbon chain length, and changes in the stereochemistry, were tested to probe the role of ceramide's molecular features on its ability to form channels in these two different membrane types. The ability to permeabilize the MOM was relatively insensitive to modifications of the various functional groups of ceramide whereas the same modifications resulted in plasma membrane permeabilization (a gain of function rather than a loss of function). Some analogs (ceramine, NBD-labeled ceramide, $\mathrm{C}_{18,1}$ ceramide) gained another function, the ability to inhibit cytochrome oxidase. The gain of deleterious functions indicates that constraints on the structure of ceramide that is formed by the cell's synthetic machinery includes the avoidance of deleterious interactions. We propose that the specific structure of ceramide limits the size of its interactome (both proteins and lipids) thus reducing the likelihood of unwanted side effects.
\end{abstract}

Keywords: ceramide channel, analog, sphingolipid, erythrocyte, mitochondria. 


\section{Introduction}

Ceramides ( $\mathrm{N}$-acylated sphingosines) are members of a structurally diverse family of lipids known as sphingolipids: chemical structures based on sphingosine (Zheng et al., 2006). Mammalian cells can synthesize a variety of different structural forms: over 50 have been demonstrated (Hannun and Obeid, 2008, 2011) not including the specialized ceramides that form part of the permeability barrier of skin (Meckfessel and Brandt, 2014). Different forms are generated at different times in different cellular locations (Hannun and Obeid, 2011) and it is clear that many of the different structural forms serve different functions. One may well conclude that the cellular chemical pathways have evolved to produce the appropriate structures for the various functions. Being water-insoluble, ceramides are membrane embedded and thus compartmentalized in different cellular membranes and so distinct functions may also be influenced by the membrane environment.

Ceramides are known to be involved in many critical cellular tasks including differentiation, growth suppression, cell senescence, and apoptosis (Zheng et al., 2006; Hannun and Obeid, 2008). Many of these functions involve ceramides acting on proteins to modify their function and activity. However, one form of ceramide, $\mathrm{C}_{16^{-}}$ ceramide ( $N$-palmitoyl-D-erythro-sphingosine, Figure 1$)$, has been shown to be able to act, without the need for proteins, (Siskind and Colombini, 2000; Siskind et al., 2003) to form large stable channels in the mitochondrial outer membrane (MOM), permeabilizing this membrane to proteins (Siskind et al., 2002, 2006; Ghafourifar et al., 1999; DiPaola et al., 2000). The channels formed in the MOM are not due to Bcl-2 family proteins 
because the same permeability is produced in mitochondria from the yeast, $S$. cerevisiae, which lacks these proteins (Siskind et al., 2008). The proteins on the MOM are not required for this permeabilization because ceramide forms these channels also in planar phosphoglycerolipid membranes (Siskind and Colombini, 2000; Siskind et al., 2003) and in liposomes (Stiban et al., 2006). That the permeability pathways formed in isolated mitochondria are the same as those produced in phosphoglycerolipid membranes, is supported by the fact that both are regulated by the proteins, $\mathrm{Bcl}-\mathrm{xL}$, CED-9, and Bax (Siskind et al, 2008; Ganesan et al., 2010), and the regulation displays he same features. The channels in the MOM and in planar membranes are also destabilized in the same was by sphingosine (Elrick et al., 2006) and dihydroceramide (Stiban et al., 2006). In addition ceramide channels were visualized by negative stain electron microscopy (Samanta et al., 2011). The sizes of the visualized channels matched the sizes calculated electrophysiological recordings of channels formed in planar membranes. In both experimental systems the channels show the same wide range of sizes with a most frequent size of $10 \mathrm{~nm}$ in diameter (Samanta et al., 2011). Further studies using microfluidic systems (Shao et al., 2012) showed that the ceramide channels could be distorted by applying lateral pressure and they would restore their shape when the pressure was reduced. Molecular dynamic simulations (Anishkin et al., 2006) indicate that the channels are stable structures. Thus, although the formation of large, stable channels in membranes by the self-assembly of hundreds of ceramide monomers is novel, the evidence for the formation of these channels is overwhelming. 
Since ceramide channels form not only in the MOM but also in phosphoglycerolopid membranes lacking proteins, it is striking that $\mathrm{C}_{16}$-ceramide fails to permeabilize the plasma membrane of erythrocytes even just to small ions (Siskind et al., 2006). From a physiological perspective, this is important because under certain conditions, sphingomyelinase activity converts sphingomyelin (a major component of the outer leaflet of the plasma membrane of mammalian cells) to ceramide in the plasma membrane (Bollinger et al., 2005; Stiban et al., 2008) and the formation of ceramide channels would permeabilize that membrane. Such a permeability would be disastrous for mammalian cells resulting in the dissipation of the $\mathrm{Na}^{+}$gradient, a major source of energy and essential for maintenance of cell volume. This manuscript investigates the possibility that this selective permeabilization by ceramide might lie, in part, in the particular structure of $\mathrm{C}_{16}$-ceramide.

To appreciate what might influence the ability to form ceramide channels, it is useful to have some insight into their structure. Except for electronmicroscopic observations, the structure of ceramide channels has been deduced from functional studies (Siskind et al., 2003) and supported with insights by the use of molecular dynamic simulations (Anishkin et al., 2006). The working model (Siskind et al., 2003; Colombini, 2013) is a barrel-stave structure where the staves are columns of six ceramide monomers linked together by hydrogen bonding of the amine linkages, similar to the bonding that forms the secondary structure of proteins. The columns are arranged in an anti-parallel fashion, allowing for favourable dipole-dipole interactions between adjacent columns. The twin hydroxyl groups of each ceramide molecule 
contribute to the polar inner surface of the channel forming a hydrogen-bonded network with water.

In order to understand the molecular basis underlying the surprising ability of ceramide to self-assemble into such a large structure synthetic analogs of ceramide were used to assess the importance of each of the features of $\mathrm{C}_{16}$-ceramide in channel formation (Perera et al., 2012a). With the indispensable aid and skills in chemical synthesis and chemical insights of Robert Bittman, Zdzislaw M. Szulc, and Alicja Bielawska, chemical analogs of ceramide were assessed for their ability to form channels in the MOM and planar phosphoglycerolipid membranes. Extensive discussions with Dr. Bittman were extremely useful in both analog design and in the interpretation of the results. Interesting and insightful differences were demonstrated between the chemical features that are reported as important in one or another cellular function of ceramide and the features important in channel formation and stability. The length of the acyl chain is critical to the physiology and this is emphasized by the chain length specificities of the various ceramide synthases found in mammalian cells (Stiban et al., 2010). In contrast acyl chain length had little effect on ceramide's channelforming ability (Perera et al., 2012a). Similarly the C4-C5 trans double bond could be replaced by other features, such as a cis double bond or a hydroxyl group (phytoceramide) and still retain channel-forming ability. Methylation of the C1 hydroxyl resulted in inability to form stable channels whereas methylation of the hydroxyl at C3 had no detectable effect. The mirror image of natural $\mathrm{C}_{16}$-ceramide (2R3S vs $2 \mathrm{~S} 3 \mathrm{R}$ ) formed channels that were rather unstable. Other changes that strengthened the hydrogen-bonding capability of ceramide resulted in a stronger channel-forming ability and the reverse was also true. Overall, channel-forming ability was less sensitive to chemical modification than expected. This is partly compensated by the specificity 
shown by $\mathrm{Bcl}-\mathrm{xL}$ and $\mathrm{Bax}$ in regulating ceramide channel formation. Using the same set of ceramide analogs, the molecular features important for channel regulation by these proteins was identified (Perera et al., 2012b). For example, Bcl-xL's ability to destabilize ceramide channels was insensitive to changes made in ceramide's polar groups but very sensitive to changes in the hydrocarbon chains. The strongest inhibitory action was on channels made with ceramides of acyl chain length between C16 and C20. By contract MOM permeabilization by ceramide and Bax synergy was very sensitive to modification of ceramide's polar regions and insensitive to changes in the hydrocarbon chains.

Here we report on the use of ceramide analogs to explore the features of $\mathrm{C}_{16^{-}}$ ceramide that are important in selective channel formation in different cellular membranes.

\section{Materials and methods}

Reagents. $\mathrm{C}_{16^{-}}$and $\mathrm{C}_{10^{-}}$-ceramide(\#1 and 14) and analogs \#13 and \#16 were purchased from Avanti Polar Lipids. The analogs of D-e- $\mathrm{C}_{16}$-ceramide (\# $\mathbf{2}$ to \#11 and \# 15 to \#17)were synthesized by Lipidomics Core, MUSC as described previously (Usta et al., 2001; Chalfant et al., 2003). Analog \# 12 was synthesized as previously described (Brockman et al, 2004; Karasavvas et al., 1996; Chun et al., 2002; He et al., 2000a, 2000b). All the ceramides were dissolved in 2-propanol for use in the experiments.

Isolation of mitochondria: Rat liver mitochondria were isolated essentially as previously described (Siskind et al., 2002). These were suspended in sucrose-free medium (280 mM mannitol, 0.1 mM EGTA, 2 mM HEPES, pH 7.4), typically to a protein 
concentration of $4-5 \mathrm{mg} / \mathrm{mL}$ and stored on ice. The intactness of the mitochondria was more than $85 \%$. The animal use protocols were approved by the Institutional Animal Care and Use Committee. The animals were euthanized by a procedure consistent with the Panel on Euthanasia of the AVMA. The animal facility used to house the animals is accredited by AAALAC.

\section{Measurement of the permeabilization of the mitochondrial outer membrane to}

cytochrome c. The permeability of the MOM to cytochrome $c$ was measured by using the cytochrome $c$ accessibility assay as previously described (Siskind et al., 2002; Wojtczak et al., 1972). The MOM is normally impermeable to proteins. If it becomes permeable by the formation of large channels by ceramide or its analogs, exogenously added reduced cytochrome $c$ can cross the outer membrane and be oxidized by cytochrome $c$ oxidase, found on the mitochondrial inner membrane. The rate of cytochrome $c$ oxidation is a measure of the MOM permeability. The stock mitochondrial suspension was diluted to $0.2 \mathrm{mg} / \mathrm{mL}$ of mitochondrial protein right before use. Then, 50 $\mu \mathrm{L}$ of this was dispersed in $650 \mu \mathrm{L}$ of the mitochondrial isolation buffer $(210 \mathrm{mM}$ Mannitol, $70 \mathrm{mM}$ Sucrose, 5 mM HEPES and $0.1 \mathrm{mM}$ EGTA, pH 7.5) supplemented with $5 \mathrm{mM} \mathrm{DNP}$ and $2 \mathrm{mM}$ antimycin A) to a final mitochondrial protein content of $10 \mu \mathrm{g}$ in $700 \mu \mathrm{L}$. The mitochondria were allowed to acclimate in this buffer for 10 minutes at room temperature before adding $15 \mu \mathrm{g}(30 \mathrm{nmol})$ of ceramide or an analog $(1 \mathrm{mg} / \mathrm{mL} 2$ propanol) while vortexing. Vortexing is necessary for effective dispersal of ceramide as it is insoluble in aqueous buffer. The mitochondria were not damaged by this procedure. After delivering ceramide, the mitochondria were incubated for $10 \mathrm{~min}$ at room 
temperature. Then reduced cytochrome $c$ was added and its initial rate of oxidation was calculated from the decrease in absorbance at $550 \mathrm{~nm}\left(\Delta \varepsilon_{\text {red-ox }}=18.5 \mathrm{mM}^{-1} \mathrm{~cm}^{-1}\right)$ for approximately the first 2 minutes.

Measurement of the release of adenylate kinase from mitochondria. Adenylate kinase is a soluble enzyme located in the mitochondrial intermembrane space. The release of this protein from isolated mitochondria indicates the formation of channels capable of allowing proteins to cross membranes. The enzymatic activity was measured as previously described (Siskind et al., 2002; Sotocassa et al., 1967) and this was expressed as a percent of the total activity released following a mild hypotonic shock. Briefly, stock mitochondria were diluted to a concentration of $0.16 \mathrm{mg}$ mitochondrial protein per $\mathrm{mL}$ of mitochondrial isolation buffer and treated with ceramide or analog by vortexing. Then the suspension was incubated at room temperature for 10 $\min$. Then the suspension was centrifuged at $18000 \mathrm{Xg}$ for $5 \mathrm{~min}$ and supernatant collected. $300 \mu \mathrm{L}$ of the supernatant was mixed with $700 \mu \mathrm{L}$ of adenylate kinase reaction mixture (10 $\mathrm{mM}$ glucose, $5 \mathrm{mM}$ ADP, $0.2 \mathrm{mM} \mathrm{NADP,} 5 \mathrm{mM} \mathrm{MgSO}_{4}, 50 \mathrm{mM}$ Tris- $\mathrm{HCl}, 10$ units each of G6P dehydrogenase and hexokinase, $\mathrm{pH}$ 7.3). The adenylate kinase activity is reported as the initial rate of increase in absorbance at 340 $\mathrm{nm}$.

Permeabilization of the erythrocyte membrane. Blood was collected immediately after decapitating Sprague-Dawley rats (prior to removal of the liver for mitochondrial isolation) into isoosmotic buffer (150 mM NaCl, 5 mM HEPES, 4 mM EGTA, pH 7.4). 
Erythrocytes were purified by differential centrifugation and stored at $4^{\circ} \mathrm{C}$ in the same buffer. An erythrocyte suspension containing 5 nmoles haemoglobin in $0.5 \mathrm{~mL}$ was treated with $30 \mu \mathrm{g}(60 \mathrm{nmol})$ either ceramide or ceramide analog and incubated at room temperature for $10 \mathrm{~min}$. The supernatant was collected after centrifugation at $18000 \mathrm{Xg}$ for 5 min at $4^{\circ} \mathrm{C} .400 \mu \mathrm{L}$ of the supernatant was mixed with $400 \mu \mathrm{L}$ of Drabkin's reagent (Sigma Technical Bulletin No. 525) and incubated for $5 \mathrm{~min}$ at room temperature. The haemoglobin content was calculated from the absorbance at $540 \mathrm{~nm}\left(\Delta \varepsilon_{\text {cyanomethemoglobin }}=\right.$ $\left.44 \mathrm{mM}^{-1} \mathrm{~cm}^{-1}\right)$. Complete haemoglobin release was measured after detergent treatment (Triton X-100, 0.5\% (w/v) final).

\section{Experiment to test for ceramide metabolism in erythrocyte membrane.}

Erythrocytes (10 nmoles haemoglobin in $0.5 \mathrm{~mL}$ ) were treated either with $30 \mu \mathrm{g}$ of D-e$\mathrm{C}_{16}$-ceramide or $\mathrm{L}-\mathrm{e}-\mathrm{C}_{16}$-ceramide, or $30 \mu \mathrm{L}$ of vehicle (2-propanol) as in the erythrocyte permeabilization experiments. The erythrocytes were sedimented at $1000 \mathrm{~g}$ for $5 \mathrm{~min}$ at $4^{\circ} \mathrm{C}$ so as not to sediment uninserted ceramide in micelles. The supernatant was discarded and pellets were frozen and analyzed for selected sphingolipids by the Lipidomics Core, MUSC.

\section{Results and Discussion}

Multiple studies have demonstrated that ceramide with either a short or a long acyl chain can form channels in phospholipid membranes (Siskind and Colombini, 2000;

Siskind et al., 2003; Samanta et al., 2011) and that this requires no protein. Bcl-2 family 
proteins do control the propensity for channel formation (Siskind et al., 2008; Ganesan et al., 2010) but are not required. Thus it is interesting that ceramide's ability to permeabilize biological membranes should exhibit remarkable specificity as to which membrane is susceptible to ceramide channel formation. It has been reported (Siskind et al., 2002, 2006) that ceramide permeabilizes the mitochondrial outer membrane but not the plasma membrane of erythrocytes. This finding must have a structural basis and therefore analogs of ceramide were used to probe whether the structure of ceramide itself could influence this specificity. Chemical analogs (Figure 2) were synthesized with changes in the physical nature of the different functional regions of the $\mathrm{C}_{16}$-ceramide molecule (Figure 1): the amide linkage, the hydroxyl groups, the trans double bond, and the acyl chains. Analogs with changes only in the stereochemistry of the chiral centers were also tested. If specific a specific feature of the ceramide molecule is critical to this specificity then modifying that feature would result in channel formation in erythrocyte membranes whereas changes in other locations would have no effect. If the stereochemistry is important then it would indicate the presence of specific binding.

Of the 17 analogs tested (Table 1), all but 3 analogs (ceramine (\#4), 1-O-methylceramide (\#7), and dihydroceramide (\#9)) were able to permeabilize the MOM sufficiently to increase the rate of oxidation of exogenously added cytochrome $c$. This oxidation requires cytochrome $c$ to cross the MOM and contact cytochrome oxidase on the outer surface of the inner membrane (Figure 3). Crossing the outer membrane is rate limiting and thus the rate of oxidation is a measure of the permeability of the outer 
membrane (Siskind et al., 2002). This permeability depends on the number and size of the channels formed by ceramide or one of its analogs. A different assay, one that measures the release if the intermembrane space protein, adenylate kinase, was able to detect permeabilization of the MOM by 1-O-methyl-ceramide (\#7) (but not by ceramine (\#4) or dihydroceramide (\#9)) indicating that this analog can form a permeability pathway although far less stable as to be undetected by the cytochrome c accessibility assay (Perera et al., 2012a).

Both $\mathrm{C}_{2^{-}}$and $\mathrm{C}_{16^{-}}$-ceramide were shown to be able to form channels in defined/model systems: liposomes (Stiban et al, 2006) and planar phospholipid membranes (Siskind et al., 2000, 2003). Some of the analogs were tested on these systems and were effective at releasing carboxyfluorescein from liposomes. \#2, \#5, \#10 and \#11 formed large channels in planar phospholipid membranes (Perera et al., 2012a).

\section{Permeabilization of mitochondrial membranes by ceramide and analogs}

The results of the MOM permeability measurements are summarized in Table 1, column 3. These are expressed relative to the value obtained with addition of $\mathrm{C}_{16^{-}}$ ceramide at the same dose and on the same batch of mitochondria. The variability in the sensitivity of isolated mitochondria from one preparation to another, required that the activity of an analog be compared to that of $\mathrm{C}_{16}$-ceramide performed in parallel. The statistical significance is shown by the number of asterisks. The results show that the structure of ceramide can be changed in many ways without abrogating its ability to 
permeabilize mitochondrial membranes. Indeed, some of the analogs had as great or greater activity than ceramide. Some of the structural changes in the ceramide analogs are more drastic in terms of changing the chemical nature of the molecule. Others, such as the changes in stereochemistry, might be expected to be milder but show substantial decreases in channel-forming activity. Nevertheless they still permeabilize the mitochondrial outer membrane.

\section{Permeabilization of plasma membranes by ceramide and its analogs}

Erythrocyte lysis was used to asses the ability of ceramide analogs to form channels in the plasma membrane. Erythrocytes were suspended in isotonic saline so that even very small channels, only capable of allowing small ions to cross the membrane would result in lysis. $\mathrm{C}_{16}$-ceramide addition resulted in no lysis as previously reported (Siskind et al., 2006) (Figure 3). Most other analogs resulted in some degree of erythrocyte lysis. The potency varied from one analog to another (Figure 3). The non-linearity of the dose-response curves is consistent with the presence of cooperativity among many ceramide molecules in order to form the channels necessary to achieve osmotic lysis. The results are listed in Table 1 so that these can be compared to the potency for permeabilizing the MOM. Note that even changes in the ceramide structure that might be considered mild in that they do not alter the polar portion of ceramide (the portion likely to be responsible for organizing the structure of the channels) such as just shortening the aliphatic chains (C10-ceramide (\#14) and $13 \mathrm{C} / \mathrm{C}_{16}$-ceramide $\left.(\# 15)\right)$ or change in the orientation of the polar groups by changing 
the chirality of the molecule (R to S configuration at C-3 (\#3)), resulted in cell lysis. This lysis requires a permeabilization of the erythrocyte membrane to the salt in the medium and is probably the result of channel formation in the plasma membrane.

Figure 4 shows the relationship between the ability to permeabilize the MOM and that of lysing erythrocytes. For the analogs that can lyse erythrocytes, there is just a mild correlation between the two abilities (correlation coef. $=0.31$ ), indicating that as long as the analog can produce any level of permeability the erythrocyte will lyse. The analogs unable to permeabilize either membrane (\#7 and \#9) or barely able to do so (\#6) are simply very poor channel formers (Perera et al., 2012). What's left is $\mathrm{C}_{16^{-}}$ ceramide (\#1). It stands out as being differentially able to permeabilize these two membranes. Note also that no substance has the opposite specificity, i.e. lyses erythrocytes but does not permeabilize the MOM.

The lack of channel formation in erythrocytes by $\mathrm{C}_{16}$-ceramide could be the result of selective metabolism of the natural product. Not only would the loss of ceramide reduce the propensity for channel formation, the metabolites, sphingosine and dihydroceramide, interfere with channel formation (Stiban et al., 2006; Elrick et al., 2006). To test for this possibility, erythrocytes were treated with either the natural (2S, $3 \mathrm{R}) \mathrm{D}-\mathrm{C}_{16}$-ceramide, $(2 \mathrm{R}, 3 \mathrm{~S}) \mathrm{L}-\mathrm{C}_{16}$-ceramide or vehicle control (2-propanol) and washed free of uninserted ceramide. When analyzed for key sphingolipids, the amount of metabolism was minimal (Table 2). The sphingosine and dihydroceramide levels were less than $0.3 \%$ and $1.2 \%$ of the ceramide levels, resp. Detectable inhibitions of 
ceramide channels were only observed at levels greater that $2.5 \%$ of the ceramide level (Stiban et al., 2006; Elrick et al., 2006). Thus the observed levels were too low to have any significant inhibition much less total inhibition of ceramide channel formation.

The inability of $\mathrm{C}_{16}$-ceramide to permeabilize the erythrocyte membrane when it permeabilizes both the MOM and phospholipids membranes (Siskind et al., 2002, 2003, 2006; Stiban et al., 2006) can be best attributed to the environment within the plasma membrane rather than a structural constraint on channel formation by the analog. The protein or lipid composition of the plasma membrane or the organization of these components could somehow suppress the propensity for channel formation by $\mathrm{C}_{16^{-}}$ ceramide. One possibility is that the ceramide that inserts into the plasma membrane is bound to a tetraspanin. Two of these proteins, CD82 and CD9 induce exosome export in a ceramide-dependent manner (Chairoungdua et al., 2010). Thus the resistance to ceramide-induced cell lysis might be a consequence of the presence of a ceramidebinding protein rather than a specific mechanism to prevent ceramide generation in the plasma membrane, resulting in cell lysis. In any event, the exact molecular mechanism by which the plasma membrane is able to resist and perhaps actively suppress channel formation merits further investigation.

\section{Side effects gained by ceramide analogs}

This same conclusion is reached, in a limited way, when examining the ability of ceramide and its analogs to influence the activity of cytochrome oxidase. Ceramide and most of its analogs have no significant effect on the rate of cytochrome $c$ oxidation by 
mitochondria whose outer membranes have been damaged by hypotonic shock. However, three analogs are potent inhibitors of cytochrome oxidase (Table 1). One is ceramine (\#4), which has a net positive charge at physiological pH. The others (\#16, 17) have bulkier hydrophobic regions. The bulkier regions may not pack well resulting in the presence of many structural conformations. Some of these may fit into the cavities of proteins, influencing their enzymatic activity. These would have a greater interactome than $\mathrm{C}_{16}$-ceramide and thus a greater propensity for side effects. Thus the selection pressure to retain the structure of ceramide should be acting to prevent unwanted collateral effects. This might be manifested as active selection against the evolution of metabolic pathways that generate elaborations on the ceramide structure at levels and in locations where they would have significant undesired effects.

Supporting evidence that ceramide analogs can result in unwanted side effects can be found in the literature. The short chain analogs $C_{2}$ and $C_{6}$-ceramide induce the mitochondrial permeability transition but the $\mathrm{C}_{16}$-ceramide does not (DiPaola et al., 2000). Indeed the long chain ceramides were reported to inhibit the permeability transition in response various stresses (Novgorodov et al., 2008). Also the short chain ceramides were found to inhibit complex III, though they do not affect complex IV (Gudz et al., 1997). Short chain ceramides also induce ROS production in isolated mitochondria by directly interacting with the respiratory chain (Garcia-Ruiz et al., 1997).

The structure of natural ceramides is determined by the cellular enzymes that make up the sphingolipid metabolic pathway. These enzymes show a high substrate 
specificity commensurate with the need to generate only specific products. Ceramide kinase and ceramidase have been studied extensively (Usta et al., 2001; Wijesinghe et al., 2005). This specificity, typical of enzymes in general, limits the range of possible molecular forms that are found in cells. Clearly, this is important when making certain molecules, such as the constituents of macromolecules such as proteins. Why is this so critical for lipids? Perhaps it is to limit the number of possible interactions and thus also the number of undesirable interactions.

There exists a very large molecularly diverse family of lipids structurally related to ceramide (Pruett et al., 2008). These are generated by a variety of cellular pathways that synthesize a wide variety of ceramide-like molecules. Each serves specific functions. For instance the ceramides found in skin are highly insoluble, contributing to the skin's barrier function (Bouwstra et al., 2006). Some organisms naturally produce analogs of ceramide in which the sphingoid backbone, the fatty amide chain, and/or the 1-OH or 3-OH group are modified. For example, fungi and plants produce phytoceramide (\#10) and lactariamides (Yue et al., 2001). Some medicinal plants produce candidamide B (Wu et al., 2009). Diatoms produce deoxyceramide 1-sulfonic acid (Anderson et al., 1978; Godchaux $3^{\text {rd }}$ et al., 1983) and some bacteria produce capnoids as major components of their envelope membrane (Godchaux $3^{\text {rd }}$ et al., 1980). These examples of unusual forms of ceramide found naturally show that other forms can be generated by cells, but natural selection has apparently excluded these from most mammalian cells. The reasons are not known but unwanted side effects are likely to be at least part of the answer. For example, phytoceramide, found commonly in 
plants and fungi, effectively permeabilizes the plasma membrane of erythrocytes (Table 1) and thus strong selection pressure must exist to either limit its channel-forming function or concentration when produced in mammalian cells (Chalfant et al., 2003).

\section{Conclusions}

The ability of $\mathrm{C}_{16}$-ceramide to permeabilize the MOM to proteins but not permeabilize the plasma membrane of erythrocytes depends both on the structure of this ceramide and on the properties of the membrane. If the biophysical characteristics of the ceramide do not favour channel formation then channels will not form in either membrane. However, multiple analogs of ceramide are capable of forming channels but some are inhibited or prevented from forming channels in the plasma membrane. The strongest inhibitory effect is on the natural compound, $\mathrm{C}_{16}$-ceramide. There must be a specific process in the plasma membrane that inhibits channel formation by this particular molecule. 


\section{Acknowledgments}

This work was supported by grants from the National Science Foundation (MCB1023008) to MC and from the National Institutes of Health (HL-083187) to R.B. L.J.S

received a Career Development Award-2 from the Veterans Administration and pilot project funding from a Veteran's Administration REAP. 


\section{References}

Anderson, R., Kates, M., and Volcani, B.E. (1978) Identification of the sulfolipids in the non-photosynthetic diatom Nitzschia alba, Biochim. Biophys. Acta. 528, 89-106.

Anishkin, A., Sukharev, S., and Colombini, M. (2006) Searching for the molecular arrangement of transmembrane ceramide channels, Biophys. J. 90, 2414-2426.

Bollinger, C.R., Teichgräber, V., and Gulbins, E. (2005) Ceramide-enriched membrane domains, Biochim. Biophys. Acta. 1746, 284-294.

Bouwstra, J.A., and Ponec, M. (2006) The skin barrier in healthy and diseased state. Biochim. Biophys. Acta, 1758, 2080-2095.

Brockman, H.L., Momsen, M.M., Brown, R.E., He, L., Chun, J., Byun, H.S., and Bittman, R. (2004) The 4,5-double bond of ceramide regulates its dipole potential, elastic properties, and packing behavior, Biophys. J. 87, 1722-1731.

Chairoungdua, A., Smith, D.L., Pochard, P., Hull, M., and Caplan, M.J. (2010) Exosome release of $\beta$-catenin: a novel mechanism that antagonizes Wnt signalling, J. Cell. Biol. 190,1079-1091.

Chalfant, C.E., Szulc, Z. M., Roddy, P., Bielawska, A., Hannun, Y. A. (2003) The structural requirements for ceramide activation of serine-threonine protein phosphatases, J. Lipid Res. 45, 496-506.

Chun, J., Li, G., Byun, H.-S., and Bittman, R. (2002) Synthesis of new trans double bond sphingolipid analogues: Delta(4,6) and Delta(6) ceramides, J. Org. Chem. 67, 2600-2605.

Colombini, M. (2013) Membrane channels formed by ceramide, Handb. Exp. Pharmacol. 215, 109-126.

Di Paola M., Cocco T., and Lorusso M. (2000) Ceramide interaction with the respiratory chain of heart mitochondria, Biochemistry 39, 6660-6668.

Di Paola, M., Cocco, T., and Lorusso, M. (2000) Ceramide interaction with the respiratory chain of mitochondria, Biochemistry. 39, 6660-6668.

Elrick, M.J., Fluss, S., and Colombini, M. (2006) Sphingosine, a product of ceramide hydrolysis by ceramidase, disassembles ceramide channels, Biophys. J. 91, 17491756.

Ganesan, V., Perera, M.N., Colombini, D., Datskovskiy, D., Chadha, K., and Colombini, M. (2010) Ceramide and activated Bax act synergistically to permeabilize the mitochondrial outer membrane, Apoptosis 15, 553-562.

Garcia-Ruiz, C., Colell, A., Mari, M., Morales, A., and Fernandez-checa, J.C. (1997) Direct effect of ceramide on mitochondrial electron transport chain leads to generation of Reactive oxygen species. Role of mitochondrial glutathione, J. Biol. Chem. 272, 11369-11377.

Ghafourifar, P., Klein, S.D., Schucht, O., Schenk, U., Pruschy, M., Rocha, S., and Richter, C. (1999) Ceramide induces cytochrome $c$ release from isolated mitochondria. Importance of mitochondrial redox state, J. Biol. Chem. 274, 60806084.

Godchaux 3rd, W., and Leadbetter, E.R. (1983) Unusual sulfonolipids are characteristic of the Cytophaga-Flexibacter group, J. Bacteriol. 153, 1238-1246. 
Godchaux III, W., and Leadbetter, E.R. (1980) Capnocytophaga spp. Contain sulfonolipids that are vnovel in procaryotes, J. Bacteriol. 144, 592-602.

Gudz, T.I., Tserng, K.Y., and Hoppel, C. L. (1997) Direct inhibition of mitochondrial respiratory chain complex III by cell-permeable ceramide, J. Biol. Chem. 272, 2415424158.

Hannun, Y.A., and Obeid, L.M. (2008) Principles of bioactive lipid signalling: lessons from sphingolipids, Nat. Rev. Mol. Cell Biol. 9, 139-150.

Hannun, Y.A., and Obeid, L.M. (2011) Many ceramides, J. Biol. Chem. 286, 2785527862.

He, L., Byun, H.-S., and Bittman, R. (2000) A stereocontrolled, efficient synthetic route to bioactive sphingolipids: synthesis of phytosphingosine and phytoceramides from unsaturated ester precursors via cyclic sulfate intermediates, J. Org. Chem. 65, 7618-7626.

He, L., Byun, H.-S., and Bittman, R. (2000) Stereoselective preparation of ceramide and its skeleton backbone modified analogues via cyclic thionocarbonate intermediates derived by catalytic asymmetric dihydroxylation of a,b-unsaturated ester precursors, J. Org. Chem. 65, 7627-7633.

Karasavvas, N., Erukulla, R.K., Bittman, R., Lockshin, R., and Zakeri, Z. (1996) Stereospecific induction of apoptosis in U937 cells by N-octanoylsphingosine stereoisomers and $\mathrm{N}$-octylsphingosine. The ceramide amide group is not required for apoptosis, Eur. J. Biochem. 236, 729-737.

Meckfessel, M.H., and Brandt, S. (2014) The structure, function, and importance of ceramides in skin and their use as therapeutic agents in skin-care products, J. Am. Acad. Dermatol. 71,177-184.

Novgorodov, S.A., Gudz, T.I., and Obeid, L. M. (2008) Long chain ceramide is a potent inhibitor of the mitochondrial permeability transition pore, J. Biol. Chem. 283, 2470724717.

Omae, F., Miyazaki, M., Enomoto, A., Suzuki, M., Suzuki, Y., Suzuki, A. (2004) DES2 protein is responsible for phytoceramide biosynthesis in the mouse small intestine, Biochem. J. 379, 687-695.

Perera, M.N., Ganesan, V., Siskind, L.J., Szulc, Z.M., Bielawski, J., Bielawska, A., Bittman, R., and Colombini, M. (2012) Ceramide channels: influence of molecular structure on channel formation in membranes, Biochim. Biophys. Acta 1818, 12911301.

Perera, M.N., Lin, S.H., Peterson, Y.K., Bielawska, A., Szulc, Z.M., Bittman, R., and Colombini, M. (2012) BAX, Bcl-xL exert their regulation on different sites of the ceramide channel, Biochem. J. 445, 81-91.

Pruett, S.T., Bushnev, A., Hagedorn, K., Adiga, M. Haynes, C.A. Sullards, M.C., Liotta, D.C., and Merrill Jr., A.H. (2008) Biodiversity of sphingoid bases ("sphingosines") and related amino alcohols, J. Lipid Res. 49, 1621-1639.

Samanta, S., Stiban, J., Maugel, T.K., and Colombini, M. (2011) Visualization of ceramide channels by transmission electron microscopy, Biochim. Biophys. Acta 1808, 1196-1201. 
Shao, C., Sun, B., Colombini, M. and DeVoe, D. (2012) Dynamics of ceramide channels detected using a microfluidic system. PLoS One 7(9), e43513.

Siskind L.J., Feinstein, L., Yu, T., Davis, J.S., Jones, D., Choi, J., Zuckerman, J.E., Tan, W., Hill, R.B., Hardwick, J.M. and Colombini, M. (2008) Anti-apoptotic Bcl-2 family proteins disassemble ceramide channels, J. Biol. Chem. 283, 6622-6630.

Siskind, L.J., and Colombini, M. (2000) The lipids $\mathrm{C}_{2}$ - and $\mathrm{C}_{16}$-ceramide form large stable channels: implications for apoptosis, J. Biol. Chem. 275, 38640-38644.

Siskind, L.J., Davoody, A., Lewin, N., Marshall, S., and Colombini, M. (2003) Enlargement and contracture of $\mathrm{C}_{2}$-ceramide channels, Biophys. J. 85,1560-1575.

Siskind, L.J., Kolesnick, R.N., and Colombini, M. (2002) Ceramide channels increase the permeability of the mitochondrial outer membrane to small proteins, J. Biol. Chem. 277, 26796-26803.

Siskind, L.J., Kolesnick, R.N., and Colombini, M. (2006) Ceramide forms channels in mitochondrial outer membranes at physiologically relevant concentrations, Mitochondrion. 6, 118-125.

Sotocassa, G.L., Kuylenstierna, B., Ernster, L., and Bergstrand, A. (1967) Separation and some enzymatic properties of the inner and outer membranes of rat liver mitochondria, Methods Enzymol. 10, 448-463.

Stiban, J., Fistere Jr., D., and Colombini, M. (2006) Dihydroceramide hinders ceramide channel formation: implications on apoptosis, Apoptosis 11, 773-780.

Stiban, J., Silva, L.C., and Futerman, A.H. (2008) Ceramide-containing membranes: the interface between biophysics and biology, Trends Glycosci. Glycotech. 20, 297-313.

Stiban, J,, Tidhar, R., and Futerman, A.H. (2010) Ceramide synthases: roles in cell physiologyand signalling, Adv. Exp. Med. Biol. 688, 60-71.

Usta, J., El Bawab, S., Roddy, P., Szulc, Z.M., Hannun, Y.A., and Bielawska, A. (2001) Structural requirements of ceramide and sphingosine based inhibitors of mitochondrial ceramidase, Biochemistry. 40, 9657-9668.

Wijesinghe, D.S., Massiello, A., Subramanian, P., Szulc, Z., Bielawska, A., and Chalfant, C.E. (2005) Substrate specificity of human ceramide kinase, J. Lipid Res. 46, 2706-2716.

Wojtczak, L., Wojtczak, A.B., Wronisze, A., and Zaluska, H. (1972) Assay for intactness of outer membrane in isolated mitochondria, Acta Biochim. Polonica. 19, 227-234.

Wu, Z.P., Chen, Y., Xia, B., Wang, M., Dong, Y.F., and Feng, X. (2009) Two novel ceramides with a phytosphingolipid and a tertiary amide structure from Zephyranthes candida, Lipids. 44, 63-70.

Yue, J.M., Fan, C.Q., Xu, J., and Sun, H.D. (2001) Novel ceramides from the fungus Lactarium volemus, J. Nat. Prod. 64, 1246-1248.

Zheng, W.J., Kollmeyer, J., Symolon, H., Momin, A., Munter, E., Wang, E., Kelly, S., Allegood, J.C., Liu, Y., Peng, Q., Ramaraju, H., Sullards, M.C., Cabot, M., and Merrill Jr., A. H. (2006) Ceramides and other bioactive sphingolipid backbones in health and disease: lipidomic analysis, metabolism and roles in membrane structure, dynamics, signaling and autophagy, Biochim. Biophys. Acta. 1758, 1864-1884. 


\section{Figure legends}

Figure 1. The structure of $(2 S, 3 R, 4 E)-\mathrm{C}_{16}$-ceramide (\#1), the naturally occurring ceramide where sphingosine is amide-linked to a 16-carbon fatty acid.

Figure 2. The structures of the analogs examined in this work are shown in detail.

Figure 3. Dose-response curves of the ability of $\mathrm{C}_{16}$-ceramide and some of the analogs to lyse erythrocytes. The vehicle control was subtracted from all the results shown.

Figure 4. Correlation between the ability of $\mathrm{C}_{16}$-ceramide or ceramide analog to permeabilize the MOM and its ability to lyse erythrocytes. The agents capable to lysing erythrocytes were plotted with filled symbols. Open symbol were used for the others. The fitted line is solely for the filled symbols. 
Table 1: The ability of ceramide and various analogs to permeabilize the outer membrane of isolated rat liver mitochondria and rat erythrocytes, and inhibit the enzymatic activity of cytochrome oxidase. The first compound (\#1) is the natural stereoisomer.

\begin{tabular}{|c|c|c|c|c|}
\hline (\#) Name & $\begin{array}{l}\text { Type of } \\
\text { change }\end{array}$ & $\begin{array}{l}\text { MOM } \\
\text { Permeabilization } \\
\text { relative to } \\
\mathrm{C}_{16} \text {-ceramide }\end{array}$ & $\begin{array}{l}\text { Erythrocyte } \\
\text { Lysis (\%) }^{a} \\
\text { mean } \pm \\
\text { S.D. }\end{array}$ & $\begin{array}{l}\text { Oxidase } \\
\text { Inhibition }\end{array}$ \\
\hline $\begin{array}{l}\text { (1) }(2 S, 3 R, 4 E) \mathrm{C}_{16^{-}} \\
\text {ceramide }\end{array}$ & $\begin{array}{l}\text { stereo- } \\
\text { chemistry }\end{array}$ & 1 & $<2$ & No \\
\hline $\begin{array}{l}\text { (2) }(2 R, 3 S, 4 E) \mathrm{C}_{16^{-}} \\
\text {ceramide }\end{array}$ & & $0.16 \pm 0.04^{* *}$ & $18 \pm 0.1^{\star \star \star}$ & No \\
\hline $\begin{array}{l}\text { (3) }(2 S, 3 S, 4 E) \mathrm{C}_{16^{-}} \\
\text {ceramide }\end{array}$ & & $0.80 \pm 0.09 *$ & $32 \pm 2^{\star \star}$ & No \\
\hline $\begin{array}{l}\text { (4) }(2 S, 3 R, 4 E) \mathrm{C}_{16^{-}} \\
\text {ceramine }\end{array}$ & $\begin{array}{l}\text { amide } \\
\text { linkage }\end{array}$ & N/D & $48 \pm 2^{\star \star \star}$ & Yes \\
\hline $\begin{array}{l}(5)(2 S, 3 R, 4 E) \mathrm{C}_{16} \text {-urea- } \\
\text { ceramide }\end{array}$ & & $2.29 \pm 0.07^{\star \star \star}$ & $52 \pm 2^{\star \star \star}$ & No \\
\hline $\begin{array}{l}\text { (6) }(2 S, 3 R, 4 E) \mathrm{N} \text { - } \\
\text { methyl- } \mathrm{C}_{16} \text {-ceramide }\end{array}$ & & $0.21 \pm 0.04^{*}$ & $<2$ & No \\
\hline
\end{tabular}




\begin{tabular}{|c|c|c|c|c|}
\hline $\begin{array}{l}\text { (7) }(2 S, 3 R, 4 E) 1-O- \\
\text { methyl- }{ }_{16} \text {-ceramide }\end{array}$ & $\begin{array}{l}\text { hydroxyl } \\
\text { groups }\end{array}$ & $0.0^{\star \star \star}$ & $<2$ & No \\
\hline $\begin{array}{l}\text { (8) }(2 S, 3 R, 4 E) 3-O- \\
\text { methyl- }{ }_{16} \text {-ceramide }\end{array}$ & & $1.1 \pm 0.15$ & $66 \pm 7^{* \star}$ & No \\
\hline $\begin{array}{l}\text { (9) }(2 S, 3 R) C_{16} \text {-dh- } \\
\text { ceramide }^{b}\end{array}$ & $\begin{array}{l}\text { double } \\
\text { bond }\end{array}$ & $0.0^{\star \star \star \star \star}$ & $<2$ & No \\
\hline $\begin{array}{l}(10)(2 S, 3 R, 4 R) \mathrm{C}_{16^{-}} \\
\text {phytoceramide }\end{array}$ & & $2.3 \pm 0.5^{\star}$ & $24 \pm 1^{\star \star \star}$ & No \\
\hline $\begin{array}{l}\text { (11) }(2 S, 3 R) C_{16}-4,5- \\
\text { deh-ceramide }^{b}\end{array}$ & & $1.2 \pm 0.2$ & $48 \pm 2^{\star \star \star}$ & No \\
\hline $\begin{array}{l}(12)(2 S, 3 R, 4 E) \mathrm{C}_{16^{-}} \\
\text {(4,5-allene)-ceramide }\end{array}$ & & $3.0 \pm 0.26^{\star}$ & $69 \pm 1^{\star \star \star}$ & No \\
\hline $\begin{array}{l}\text { (13) }(2 S, 3 R, 15 E) C_{16^{-}} \\
d^{*} \text {-ceramide }^{b}\end{array}$ & & $3.8 \pm 0.59 * \star \star$ & $57 \pm 5^{\star \star}$ & No \\
\hline $\begin{array}{l}\text { (14) }(2 S, 3 R, 4 E) \mathrm{C}_{10^{-}} \\
\text {ceramide }\end{array}$ & $\begin{array}{l}\text { acyl } \\
\text { chains }\end{array}$ & $6.6 \pm 0.26^{\star \star \star}$ & $87 \pm 0.5^{\star \star \star}$ & No \\
\hline $\begin{array}{l}\text { (15) }(2 S, 3 R, 4 E) \\
13 C / C_{16} \text {-ceramide }\end{array}$ & & $6.1 \pm 0.27^{\star \star \star}$ & $43 \pm 2^{\star \star \star}$ & No \\
\hline $\begin{array}{l}(16)(2 S, 3 R, 4 E) \mathrm{C}_{6^{-}} \\
\text {NBD-ceramide }\end{array}$ & & N/D & $13 \pm 5^{\star^{c}}$ & Yes \\
\hline $\begin{array}{l}\text { (17) }(2 S, 3 R, 4 E) \mathrm{C}_{18: 1^{-}} \\
\text {ceramide }\end{array}$ & & $\mathrm{N} / \mathrm{D}$ & $42 \pm 3^{\star \star}$ & Yes \\
\hline
\end{tabular}


${ }^{a}$ Statistical significance was determined using the Student's $t$ test and the $P$ values are as follows: ${ }^{*}<.05,{ }^{* \star}<.01,{ }^{* \star *}<.001$; values are given as mean \pm SE of at least 3 experiments;

${ }^{b} \mathrm{dh}$ is dihydro; deh is dehydro/triple bond

${ }^{c}$ The dose of the analog was 10 times less than for the rest.

N/D: not done 
Table 2. Ceramide metabolites following treatment of erythrocytes with $\mathrm{C}_{16}$-ceramide. The percentages reported relate the amounts of either sphingosine or dihydroceramide to the amount of ceramide.

\begin{tabular}{|c|c|c|c|c|}
\hline Sample & $\mathrm{C}_{16}$-ceramide & $\mathrm{C}_{16}$-dihydrocer. & sphingosine & dihydrosphingosine \\
\hline & \multicolumn{4}{|l|}{ picomoles } \\
\hline vehicle & 0.7 & 0.9 & 3.1 & 2.9 \\
\hline vehicle & 0.0 & 0.1 & 2.1 & 2.6 \\
\hline D-e- $C_{16}$ cer & 2206 & $24.9(1.1 \%)$ & $3.9(0.17 \%)$ & 1.4 \\
\hline D-e- $C_{16}$ cer & 2340 & $23.3(1.0 \%)$ & $5.2(0.22 \%)$ & 1.8 \\
\hline L-e-C $\mathrm{C}_{16}$ cer & 2287 & $\begin{array}{ll}2.3 & (0.1 \%)\end{array}$ & $2.6(0.11 \%)$ & 1.4 \\
\hline L-e-C $_{16}$ cer & 2455 & $3.0 \quad(0.1 \%)$ & $2.3(0.09 \%)$ & 1.9 \\
\hline
\end{tabular}




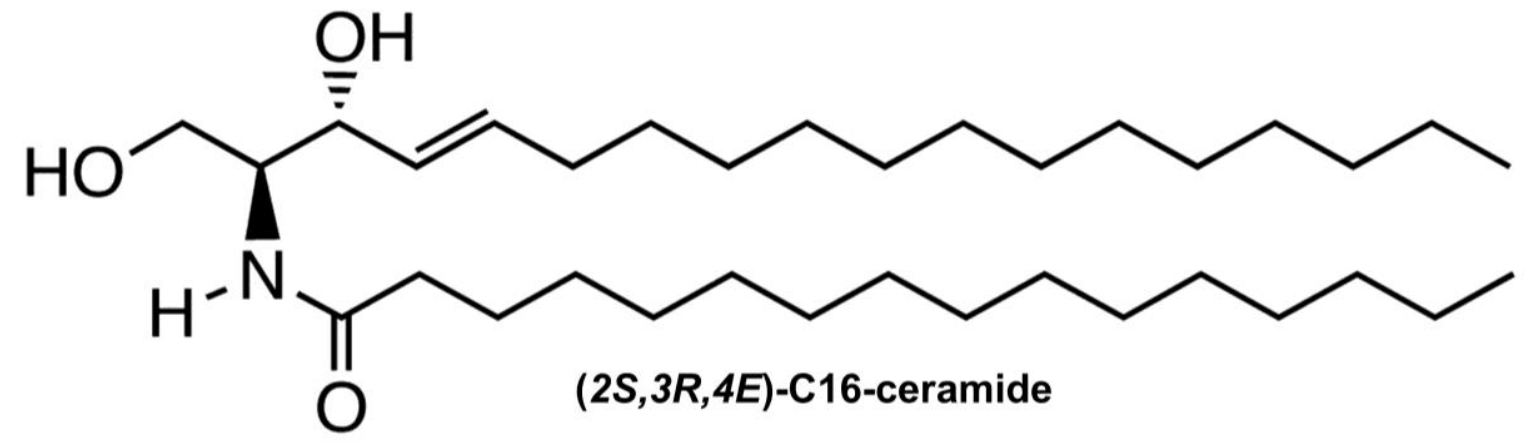

Figure 1 

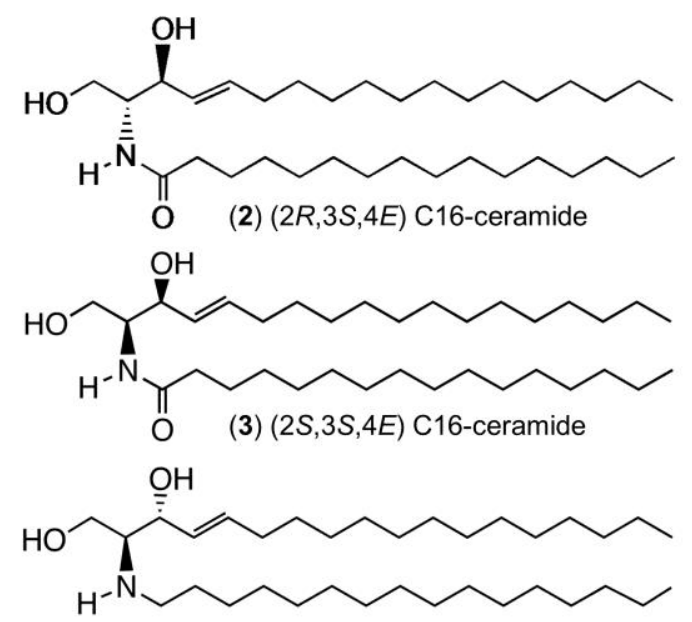

(4) $(2 S, 3 R, 4 E)$ C16-ceramine
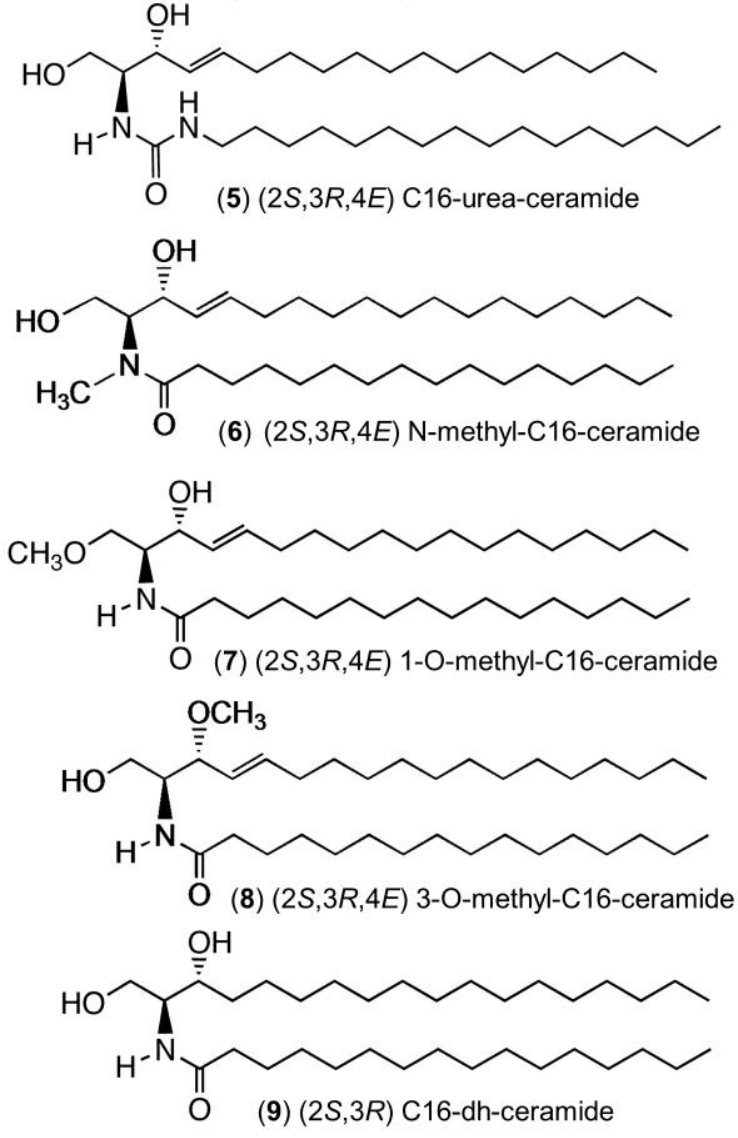
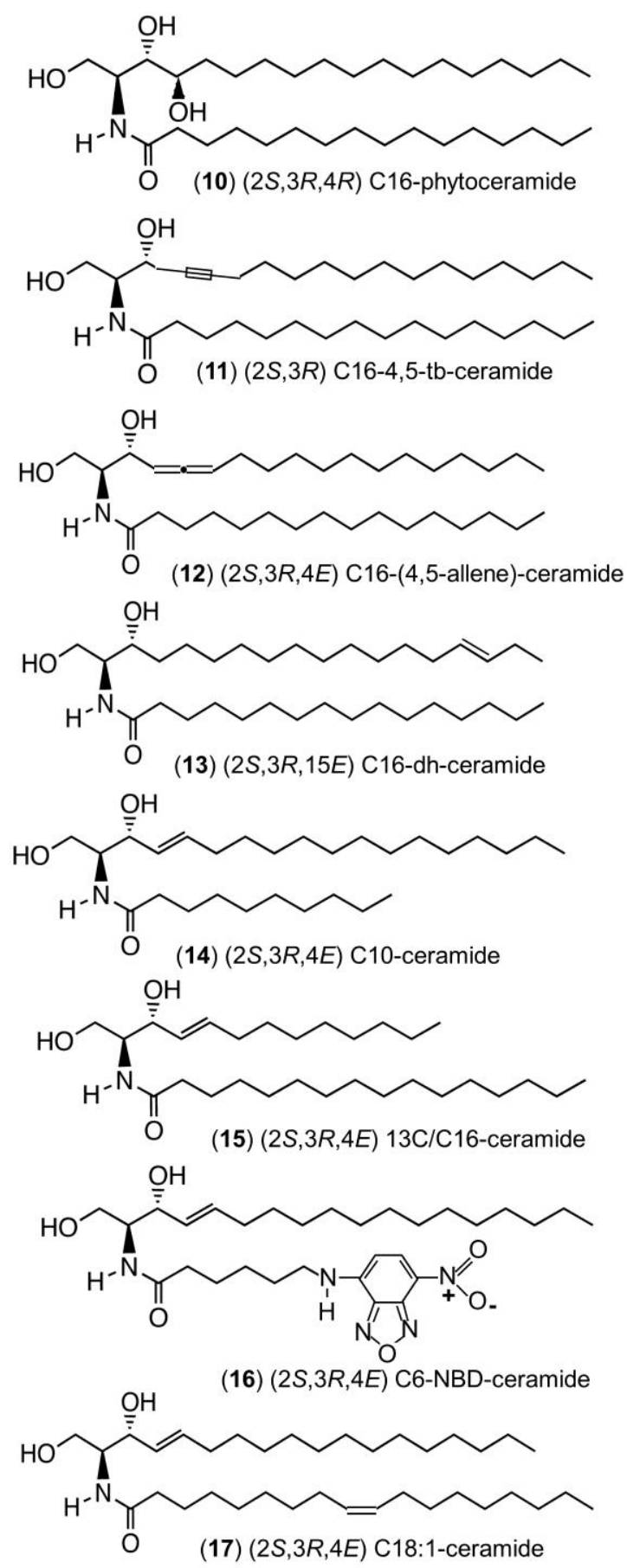

Figure 2 

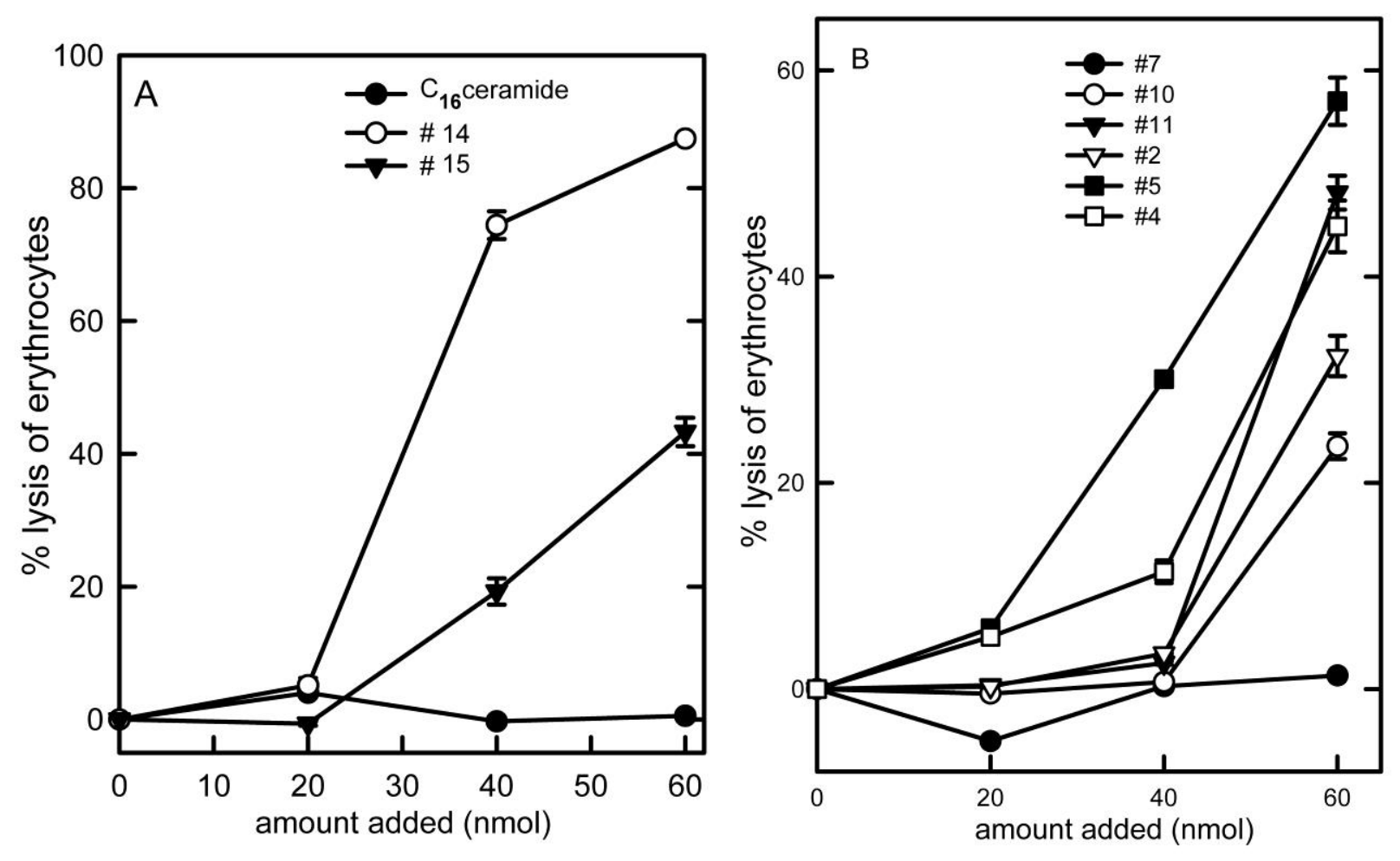

Figure 3 


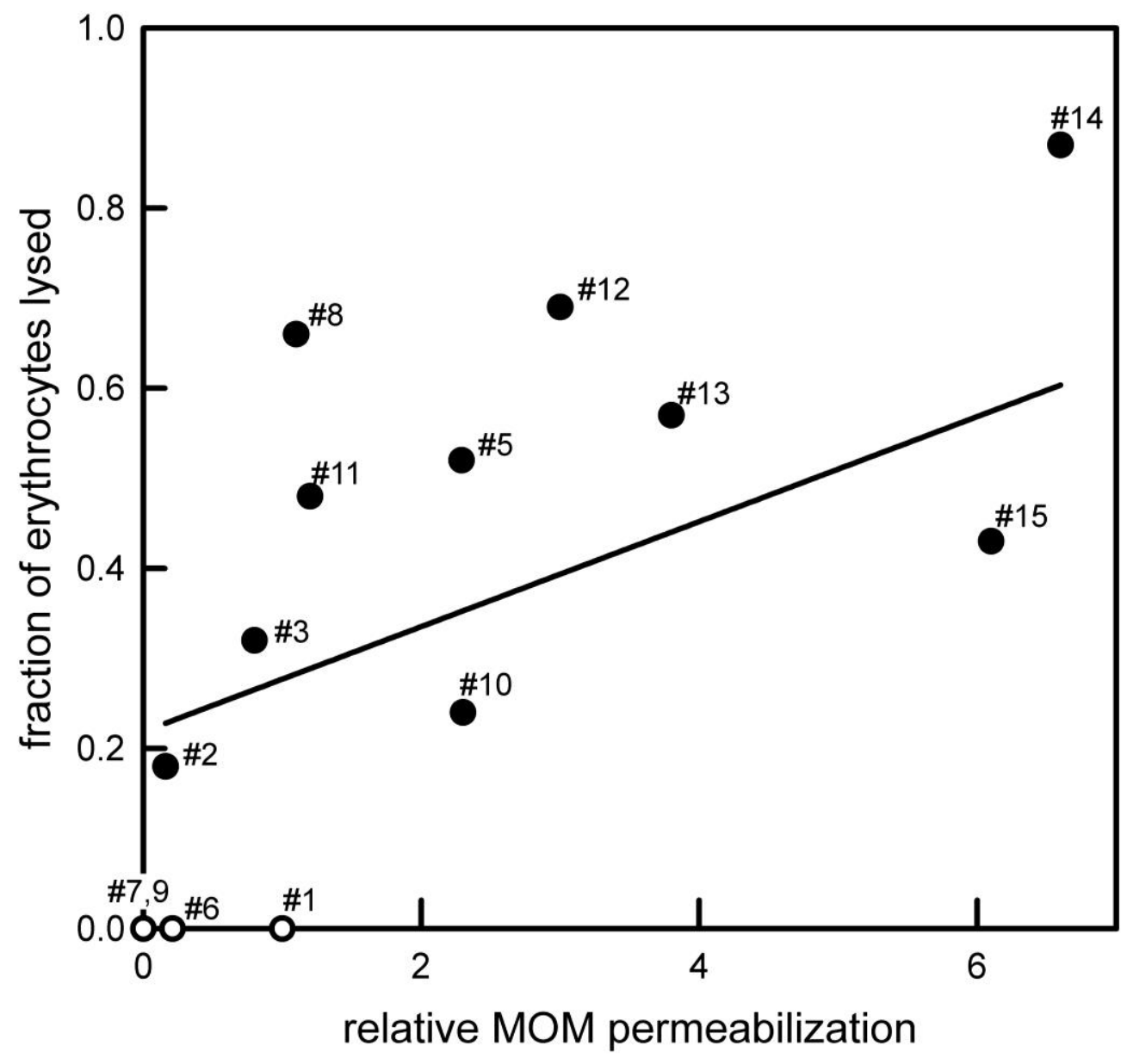

Figure 4 
